\title{
Investigation of perfusion defects by Q-SPECT/CT in patients with mild-to-moderate course of COVID-19 and low clinical probability for pulmonary embolism
}

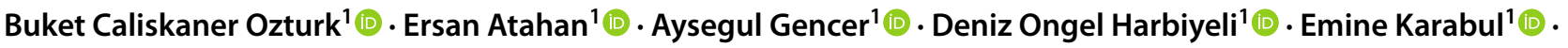

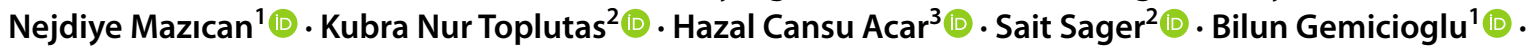 \\ Sermin Borekci ${ }^{1}$ (D)
}

Received: 12 May 2021 / Accepted: 17 June 2021 / Published online: 25 June 2021

(c) The Japanese Society of Nuclear Medicine 2021

\begin{abstract}
Objective Pulmonary embolism is a severe source of mortality and morbidity in patients with severe and critical coronavirus disease 2019. It is not yet clear whether the tendency to thrombosis is increased in the mild-to-moderate course of COVID-19. Our research aims to show the clinical benefit of Q-SPECT/CT in diagnosing PD in outpatients treated with mild-to-moderate course of COVID-19 and to determine the frequency of perfusion defects in these patients having relatively lower risk.

Methods All patients who underwent Q-SPECT/CT with suspicion of embolism were examined retrospectively. Only patients with low clinical probability and mild-to-moderate course of COVID-19 for PE were included in the study. The patients were evaluated comparatively as those with and without perfusion defects. Patients were divided into laboratory suspicion, clinical suspicion, or clinical and laboratory suspicion.

Results In outpatients with mild-to-moderate COVID-19 with low clinical probability for PE, PD without CT abnormality was detected with a rate of $36.6 \%$ with Q-SPECT/CT performed for complaints of high D-dimer and/or dyspnea. None of the patients had PD at more proximal level than the segment level. PD with no concomitant CT abnormality was observed with a rate of $56.5 \%$ in patients with both clinical and laboratory suspicion. For D-dimer $=0.5 \mathrm{mg} / \mathrm{dL}$ cut-off sensitivity is $85 \%$, for D-dimer $=1.5 \mathrm{mg} / \mathrm{dL}$ cut-off specificity $81 \%$.

Conclusion Thrombosis tendency is also present in outpatients with mild-to-moderate COVID-19, and these patients should also be offered anticoagulant prophylaxis during the COVID-19 period.
\end{abstract}

Keywords COVID-19 $\cdot$ Q-SPECT/CT $\cdot$ Pandemic $\cdot$ Pulmonary embolism $\cdot$ Perfusion defects

Sermin Borekci

borekcisermin@gmail.com

Buket Caliskaner Ozturk

drbuketcaliskaner@hotmail.com

Ersan Atahan

ersanatahan@gmail.com

Aysegul Gencer

aysegulbozkurtgencer@gmail.com

Deniz Ongel Harbiyeli

denizong@gmail.com

Emine Karabul

karabullemine@gmail.com

Nejdiye Mazıcan

nejdiyegungordu@gmail.com

Kubra Nur Toplutas

kubra.toplutas@istanbul.edu.tr
Hazal Cansu Acar

hazalcansu@gmail.com

Sait Sager

saitsager@yahoo.com

Bilun Gemicioglu

bilung@gmail.com

1 Department of Pulmonary Diseases, Istanbul UniversityCerrahpasa, Cerrahpasa Faculty of Medicine, 34303 Istanbul, Turkey

2 Department of Nucleer Medicine, Istanbul University-Cerrahpasa, Cerrahpasa Faculty of Medicine, Istanbul, Turkey

3 Department of Public Health, Istanbul University-Cerrahpasa, Cerrahpasa Faculty of Medicine, Istanbul, Turkey 


\begin{tabular}{|c|c|}
\hline \multicolumn{2}{|c|}{ Abbreviations } \\
\hline CTPA & $\begin{array}{l}\text { Computed tomography pulmonary } \\
\text { angiography }\end{array}$ \\
\hline COVID-19 & Coronavirus disease 2019 \\
\hline MSKCC & Memorial Sloan Kettering Cancer Center \\
\hline PCR & Polymerase chain reaction \\
\hline PE & Pulmonary embolism \\
\hline $\mathrm{PD}$ & Perfusion defect \\
\hline rtPCR & $\begin{array}{l}\text { Reverse transcriptase-polymerase chain } \\
\text { reaction }\end{array}$ \\
\hline SARS-CoV-2 & $\begin{array}{l}\text { Severe Acute Respiratory Syndrome } \\
\text { causing Coronavirus }\end{array}$ \\
\hline Q-SPECT/CT & $\begin{array}{l}\text { Perfusion-single photon emission com- } \\
\text { puted tomography/computed tomography }\end{array}$ \\
\hline Tc-99m MAA & $\begin{array}{l}\text { Technetium } 99 \mathrm{~m} \text { macro-aggregates } \\
\text { albumin }\end{array}$ \\
\hline
\end{tabular}

\section{Introduction}

From the early stages of the pandemic, pulmonary embolism (PE) has been reported as a severe source of mortality and morbidity in patients with severe and critical coronavirus disease 2019 (COVID-19). In different studies, PE rates in computed tomography pulmonary angiography (CTPA) in hospitalized and critically ill patients with COVID-19 pneumonia vary between $23-31 \%$ [1-3]. However, according to the National Health Commission (7th ed.) (In Chinese) [4], pulmonary thromboembolism in patients with mild-tomoderate COVID-19. Publications related to it are limited. Whether the thrombosis tendency has increased in every patient, regardless of the severity of COVID-19, remains an open question. A study reported that PE was diagnosed with CTPA at a rate of $18 \%$ in patients with mild and moderate COVID-19 at their admission to the emergency department [5].

Perfusion single-photon emission computed tomography / computed tomography (Q-SPECT/CT); has higher accuracy than ventilation/perfusion scintigraphy in diagnosing PE [6, 7]. It is a reliable and effective method for the accelerated, high-accuracy diagnosis of acute PE [6, 7]. Based on CT component and lung images, as well as COVID-19 pneumonia; Additional comments can be made on parenchymal, pleural, and chest wall abnormalities.

It is recommended not to perform ventilation evaluation during the pandemic period [8]. Perfusion is evaluated, and PE can be safely ruled out with normal planar perfusion images. Q-SPECT/CT is recommended when planar perfusion images show abnormalities [8]. According to the Memorial Sloan Kettering Cancer Center (MSKCC) Q-SPECT/CT criteria [6, 9]. Q-SPECT/CT is recommended as an alternative diagnostic method to CTPA in the pandemic [10-13].
Dyspnea and chest pain complaints that started during COVID-19 and D-dimer elevations may continue in the post-COVID period. However, it is unknown whether the reason for these complaints is vascular damage, interstitial involvement, or dyspnea sensation secondary to muscle fatigue accompanied by myalgia. Patients with low Wells score, high D-dimer levels, chest pain, and effort dyspnea are frequently encountered.

Perfusion scintigraphy; is a reliable method to exclude embolism in patients with low clinical probability. Besides, Q-SPECT/CT can detect small peripheral thrombi with high sensitivity. Q-SPECT/CT may be the first-choice imaging method in patients with a low clinical probability of suspected PE due to COVID-19. Furthermore, the preference of Q-SPECT/CT will help to reduce the excessive workflow of computerized tomography units, which is already overloaded in the pandemic period. On the other hand, patients who have recently had chest CT for COVID-19 will also be protected from the second dose of radiation. It has been shown that Q-SPECT/CT is a method that can be safely preferred for the diagnosis of PE in patients with medium-high Wells scores with COVID-19 [14].

Our research aims to show the clinical benefit of Q-SPECT/CT in diagnosing PE in outpatients treated with mild-to-moderate course of COVID-19 and to determine the frequency of perfusion defect (PD) without CT abnormality in these patients having relatively lower risk.

\section{Material and method}

\section{Study design and settings}

It is a retrospective, cross sectional, real-life study conducted in a university hospital between April 1, 2020 and February $1,2021$.

Approval was obtained from the ethics committee of the university, dated 08.02.2021 and numbered 25,84.

\section{Participants}

\section{Inclusion criteria}

Being older than 18 , having received the diagnosis of COVID-19 with Severe Acute Respiratory Syndrome causing Coronavirus (SARS-Cov-2) polymerase chain reaction (PCR) positivity, having COVID-19 mild or moderate [4], suspicion of PE in outpatient admission It was determined as having Q-SPECT/CT imaging performed with, having the score of a low well $(<2)$ at the time of Q-SPECT/CT request. 


\section{Exclusion criteria}

Being under the age of 18, having a diagnosis of COVID-19 without PCR positivity, having had COVID-19 at a severe or critical level [4], having a medium or high Wells score at the time of Q-SPECT/CT request $(>2)$ was determined.

\section{Variables}

The diagnosis of COVID-19 was made by PCR imaging of viral RNAs isolated from nasopharyngeal swabs. Since the patients have a low clinical probability for $\mathrm{PE}$, values above $1 \mathrm{mg} / \mathrm{dL}$ for D-dimer were considered high [15].

COVID-19 weights of patients were classified according to by National Health Commission (7th ed.) (In Chinese) [4]: (1) Mild type: mild clinical symptoms without pneumonia in imaging; (2) moderate type: fever and respiratory symptoms with radiological findings of pneumonia; (3) severe type: respiratory distress ( $\geq 30$ breaths/min; oxygen saturation $\leq 93 \%$ at rest; arterial partial pressure of oxygen $(\mathrm{PaO} 2) /$ fraction of inspired oxygen $(\mathrm{FiO} 2) \leq 300 \mathrm{mmHg}$ $(1 \mathrm{mmHg}=0.133 \mathrm{kPa})$; cases with chest imaging that shows obvious lesion progression within $24-48 \mathrm{~h}>50 \%$ shall be managed as severe cases; (4) critical type: respiratory failure requiring mechanical ventilation, shock, and other organ failure requiring ICU monitoring and treatment.

\section{Imaging protocols and acquisition}

Lung perfusion scintigraphy images were performed approximately $20 \mathrm{~min}$ after the injection of 3-5 mCi Technetium 99m labeled macro aggregated albumin (Tc-99m MAA) with planar and subsequent SPECT/CT images. Tc-99m MAA syringe was prepared just before the patient's arrival, and the patient was injected in the supine position to prevent sedimentation of macroaggregates into the lung bases. Imageries were made using a Siemens (Symbia T16, Hoffman Estates, IL, USA) gamma camera. Some of the planar imaging deficiencies have been overcome by utilizing the SPECT imaging method, and diagnostic accuracy has been achieved. High-resolution diagnostic images were obtained by performing attenuation correction and anatomical localization utilizing a CT scanner thanks to the hybrid SPECT/ CT device. CT imaging was performed with IV non-contrast. Q-SPECT/CT imaging data and corresponding equivalent CT image slices were merged and imaged in axial, coronal, and sagittal planes.

\section{Image interpretation}

Lung Q-SPECT/CT images were evaluated at different times by two different Nuclear Medicine specialists. Afterward, interpretation was made by achieving a common consensus for each patient. In Q-SPECT/CT images, segmental or subsegmental perfusion defects of more than $50 \%$ of a segment not observed on CT images, defects seen in all three orthogonal planes without abnormality in the corresponding $\mathrm{CT}$ images were considered positive imaging findings.

\section{Data collection}

Patients' identity information, demographic characteristics, COVID-19 histories, COVID-19 swab results, D-dimer levels, presence of dyspnea and chest pain, Wells scores, pulmonary perfusion scintigraphy, and Q-SPECT/CT data, if performed, are collected from patient files and hospital system was obtained. If no documentation was available for a Wells score component, the data was deemed to be incomplete.

\section{Study size}

All patients found to meet the inclusion criteria between the specified dates were included in the study. Patients with and without emboli were compared among themselves. D-dimer $>1 \mathrm{mg} / \mathrm{dL}$ was considered high as the patients had low clinical probability. According to the patients' pre-diagnosis of embolism; Laboratory suspicion (D-dimer $1 \mathrm{mg} / \mathrm{dL}$ without symptoms), clinical suspicion (dyspnea and chest pain when D-dimer $<1$ ), and those with clinical and laboratory suspicion together were divided into three groups.

\section{Statistical methods}

SPSS v.21 (SPSS Inc., Chicago, IL, USA) program was used to analyze the study data. The compliance of the data to normal distribution was evaluated using the Shapiro Wilk test. Continuous variables were represented as mean \pm standard deviation and median (minimum-maximum). Frequency and percentage (\%) were used in the display of categorical variables. According to the data distribution, the Mann-Whitney $U$ test or Student $t$ test was used to compare continuous variables between groups. Categorical variables were evaluated using the Chi-squared test and Fisher's exact test. Possible risk factors for PE were evaluated by logistic regression analysis. Results are given as odds ratio (OR) and 95\% confidence interval $(95 \% \mathrm{CI})$. Cut-off values for D-dimer level were evaluated with Receiver Operating Characteristic (ROC). The significance level was accepted as $p<0.05$.

\section{Results}

\section{Participants}

Files of 143 patients who had Q-SPECT/CT performed between the specified dates were found. Forty-two patients 
were excluded because their Wells score was medium or high, 9 of them had severe and critical COVID-19, and 15 of the remaining 92 patients were not included because their data could not be reached. Seventy-seven patients with a low Wells score $(<2)$ had a mild or moderate course of COVID19 and underwent Q-SPECT/CT with a pre-diagnosis of PE during outpatient admission; the emergency or outpatient clinic was included in the study.

\section{Descriptive data}

Of the 77 patients participating in the study, 37.7\% $(n=29)$ were male and $62.3 \%(n=48)$ were female. The average age of the patients was $53.9 \pm 13.6$. While $18.9 \%(n=14)$ of the patients were active smokers, $13.5 \%(n=10)$ were exsmoker and $67.6 \%(n=50)$ were non-smoker. Lifetime cigarette consumption was $9.1 \pm 17$ pack-years. $17.6 \%(n=13)$ of the patients were using acetyl salicilic acid for neurological and / or cardiac indications prior to COVID-19 infection. One $(1.1 \%)$ patient had active malignancy.

$54.5 \%(n=42)$ of the patients had dyspnea and / or chest pain complaints before the scintigraphy. $29.9 \%$ of the patients $(n=23)$ had at least one symptom and an elevation of D-dimer $(1 \mathrm{mg} / \mathrm{dL})$. The mean D-dimer level was $2.1 \pm 3.5 \mathrm{mg} / \mathrm{dL}$. D-dimer level was above $1 \mathrm{mg} / \mathrm{dL}$ in $45.5 \%(n=35)$ of the patients. $54.5 \%(n=42)$ of the patients had clinical suspicion (chest pain and / or dispnea), $15.6 \%(n=12)$ laboratory suspicion (D-dimer $\geq 1 \mathrm{mg} / \mathrm{dL}$ ), $29.9 \%(n=23)$ was directed to Q-SPECT/CT with clini$\mathrm{cal}+$ laboratory suspicion. Perfusion scintigraphy of 5.2\% $(n=4)$ patients was completely natural and SPECT / CT was not required. The mean time between the diagnosis of COVID-19 and PD diagnosis of the patients was $47 \pm 34.4$ (minimum-maximum: 15-155) days. The demographic and clinical characteristics of the patients are shown in Table 1.

\section{Outcomes data}

PD was detected in $36.6 \%$ ( $n: 28)$ of all patients. The mean age of the patients with PD was 54.2 $\pm 14.8,67.9 \%(n=19)$ were women. The mean cigarette pack-year in those with PD was $7.8 \pm 20$. Nineteen patients $(76 \%)$ were non-smoker, three patients $(12 \%)$ were ex-smokers, three patients (12\%) were smokers (Table 1 ).

When the groups with and without PD were compared, no statistically significant difference was found between age, gender, presence of DM or HT, smoking, acetyl salicilic acid use before COVID, and presence of PD ( $p>0.05)$ (Table 1).

\section{Main results}

PD was found in $41.7 \%$ (5/12) of asymptomatic patients with only elevated D-dimer levels. PD was present in $23.8 \%$
(10/42) of the patients who did not have high D-dimer levels but had symptoms. PD was observed with a rate of $56.5 \%$ $(13 / 23)$ in patients with both clinical and laboratory suspicion. There was no significant difference between PD patients and those without PD regarding chest pain frequency and dyspnea $(p>0.05)$. The mean D-dimer was 2.6 $\pm 3.9 \mathrm{mg} / \mathrm{dL}$ with PD and $1.7 \pm 3.2 \mathrm{mg} / \mathrm{dL}$ in the group without PD. In the group with PD, the rate of those with D-dimer level $\geq 1 \mathrm{mg} / \mathrm{dL}$ was significantly higher ( $p=$ $0.005)$. D-dimer was $<1 \mathrm{mg} / \mathrm{dL}$ in $35.7 \%(n=10)$ of the patients with PD, and PD was considered due to ongoing chest pain and/or shortness of breath in these patients. Segment involvement was present in $32.1 \%(n=9)$ of 28 patients diagnosed with PD, 67.9\% $(n=19)$ had subsegment involvement, none of the patients had PD mid-level than the segment level. A few sample Q-SPECT/CT images can be seen in figüres (Figures 1,2,3).

In patients with a diagnosis of PD, no statistically significant difference was found between the defect in the form of a segment or subsegment and the suspicion type $(p>0.05)$ (Table 2).

The risk of PD in patients with D-dimer positivity is 3.4 times higher than in those without D-dimer positivity. In patients with clinical + laboratory suspicion, the risk of PD is 4.2 times higher than in patients with only clinical suspicion. In patients with laboratory suspicion, the risk of PD is 2.3 times more than in patients with a clinical suspicion. (Table 3).

For D-dimer $=0.5 \mathrm{mg} / \mathrm{dL}$ cut-off sensitivity is $85 \%$, specificity is $27 \%$, for D-dimer $=1 \mathrm{mg} / \mathrm{dL}$ cut-off sensitivity is $64 \%$, specificity is $65 \%$, for D-dimer $=1.5 \mathrm{mg} / \mathrm{dL}$ cut-off sensitivity is $44 \%$, specificity $81 \%$ (Fig. 4) (AUC (0.668)).

\section{Discussion}

In our study, in outpatients with mild-to-moderate course of COVID-19 with low clinical probability for PE, perfusion defect without CT abnormality was detected with a rate of $36.6 \%$ with Q-SPECT/CT performed for complaints of high D-dimer and/or dyspnea. In the post-COVID period, patients with high D-dimer and/or dyspnea/chest pain complaints despite low clinical probability scores, segment and subsegment involvement PD should be considered, and further investigations should be performed.

Complaints of chest pain and dyspnea may continue in the post-COVID period. A study conducted shows that in the second month after COVID-19, 43.4\% of the patients had dyspnea, and $21.7 \%$ of them continued to have chest pain [16]. In our study, $84.4 \%$ of the patients who underwent Q-SPECT/CT for suspected PE had at least one of the complaints of chest pain or dyspnea. High D-dimer levels $(1 \mathrm{mg} / \mathrm{dL})$ were accompanied by clinical suspicion in $29.9 \%$ 
Table 1 Clinical and demographic features of the study population

\begin{tabular}{|c|c|c|c|c|}
\hline & $\begin{array}{l}\text { Total } \\
(n, \% \text { or } \mathrm{SD})\end{array}$ & $\begin{array}{l}\text { No PD on } \\
\text { Q-SPECT/CT } \\
(n, \% \text { or SD) }\end{array}$ & $\begin{array}{l}\text { PD on } \mathrm{Q}-\mathrm{SPECT} / \mathrm{CT} \\
(n, \% \text { or } \mathrm{SD})\end{array}$ & $p$ value \\
\hline & $n=77$ & $n=49$ & $n=28$ & \\
\hline Age & $\begin{array}{l}52.9 \pm 13.6 \\
54(20-86)\end{array}$ & $\begin{array}{l}52.1 \pm 12.9 \\
50(27-78)\end{array}$ & $\begin{array}{l}54.2 \pm 14.8 \\
56.5(20-86)\end{array}$ & $0.515^{\mathrm{a}}$ \\
\hline Sex & & & & $0.450^{\mathrm{b}}$ \\
\hline Male & $29(37.7)$ & $20(40.8)$ & $9(32.1)$ & \\
\hline Female & $48(62.3)$ & $29(59.2)$ & $19(67.9)$ & \\
\hline Hypertension & & & & $0.162^{b}$ \\
\hline$(-)$ & $53(70.7)$ & $32(65.3)$ & $21(80.8)$ & \\
\hline$(+)$ & $22(29.3)$ & $17(34.7)$ & $5(19.2)$ & \\
\hline Diabetes mellitus & & & & $0.595^{\mathrm{b}}$ \\
\hline$(-)$ & $61(81.3)$ & $39(79.6)$ & $22(84.6)$ & \\
\hline$(+)$ & $14(18.7)$ & $10(20.4)$ & $4(15.4)$ & \\
\hline Smoking & & & & $0.499^{c}$ \\
\hline Non-smoker & $50(67.6)$ & $31(63.3)$ & $19(76)$ & \\
\hline Ex-smoker & $10(13.5)$ & $7(14.3)$ & $3(12)$ & \\
\hline Smoker & $14(18.9)$ & $11(22.4)$ & $3(12)$ & \\
\hline Pack-year (cigarette) & $\begin{array}{l}9.1 \pm 17 \\
0(0-80)\end{array}$ & $\begin{array}{l}9.7 \pm 15.5 \\
0(0-50)\end{array}$ & $\begin{array}{l}7.8 \pm 20 \\
0(0-80)\end{array}$ & $0.396^{\mathrm{d}}$ \\
\hline Using acetyl salicilic acid & & & & $0.637^{\mathrm{b}}$ \\
\hline$(-)$ & $61(82.4)$ & $38(80.9)$ & $23(85.2)$ & \\
\hline$(+)$ & $13(17.6)$ & $9(19.1)$ & $4(14.8)$ & \\
\hline PE suspicion & & & & $0.030^{b}$ \\
\hline Laboratory (D-dimer $\geq 1 \mathrm{mg} / \mathrm{dL})$ & $12(15.6)$ & $7(14.3)$ & $5(17.9)$ & \\
\hline Clinical (dispnea/chest pain) & $42(54.5)$ & $32(65.3)$ & $10(35.7)$ & \\
\hline Laboratory + Clinical & $23(29.9)$ & $10(20.4)$ & $13(46.4)$ & \\
\hline Chest pain & & & & $0.056^{\mathrm{b}}$ \\
\hline$(-)$ & $33(42.9)$ & $17(34.7)$ & $16(57.1)$ & \\
\hline$(+)$ & $44(57.1)$ & $32(65.3)$ & $12(42.9)$ & \\
\hline Dispnea & & & & $0.294^{\mathrm{b}}$ \\
\hline$(-)$ & $22(28.6)$ & $16(32.7)$ & $6(21.4)$ & \\
\hline$(+)$ & $55(71.4)$ & $33(67.3)$ & $22(78.6)$ & \\
\hline D-Dimer level & $2.1 \pm 3.51(0.2-19.7)$ & $\begin{array}{l}1.7 \pm 3.2 \\
0.7(0.2-17)\end{array}$ & $\begin{array}{l}2.6 \pm 3.9 \\
1.3(0.2-19.7)\end{array}$ & $0.014^{\mathrm{d}}$ \\
\hline D-Dimer pozitivity $(\geq 1 \mathrm{mg} / \mathrm{dL})$ & & & & $0.012^{b}$ \\
\hline$(-)$ & $42(54.5)$ & $32(65.3)$ & $10(35.7)$ & \\
\hline$(+)$ & $35(45.5)$ & $17(34.7)$ & $18(64.3)$ & \\
\hline Q-SPECT/CT date-COVID-19 date (day) & $\begin{array}{l}47 \pm 34.4 \\
(15-155)\end{array}$ & $\begin{array}{l}50 \pm 37.3 \\
37(15-155)\end{array}$ & $\begin{array}{l}37 \pm 24.3 \\
30(16-114)\end{array}$ & $0.384^{\mathrm{d}}$ \\
\hline
\end{tabular}

COVID-19 coronavirus disease 2019, PD perfusion defect, $Q$-SPECT/CT perfusion-single photon emission computed tomography/computed tomography

${ }^{\text {a }}$ Student $t$ test

${ }^{\mathrm{b}}$ Chi-squared test

${ }^{\text {c} F i s h e r ' s ~ e x a c t ~ t e s t ~}$

${ }^{\mathrm{d}}$ Mann-Whitney $U$ test

of the patients. $71.4 \%$ of all patients had dyspnea, and $27.3 \%$ of patients with dyspnea had a PD. $57.1 \%$ of all patients had chest pain, and $40 \%$ of patients with chest pain had a
PD. The rate of dyspnea and chest pain was higher in our study compared to other studies. However, our population is patients who underwent Q-SPECT/CT for the symptom 


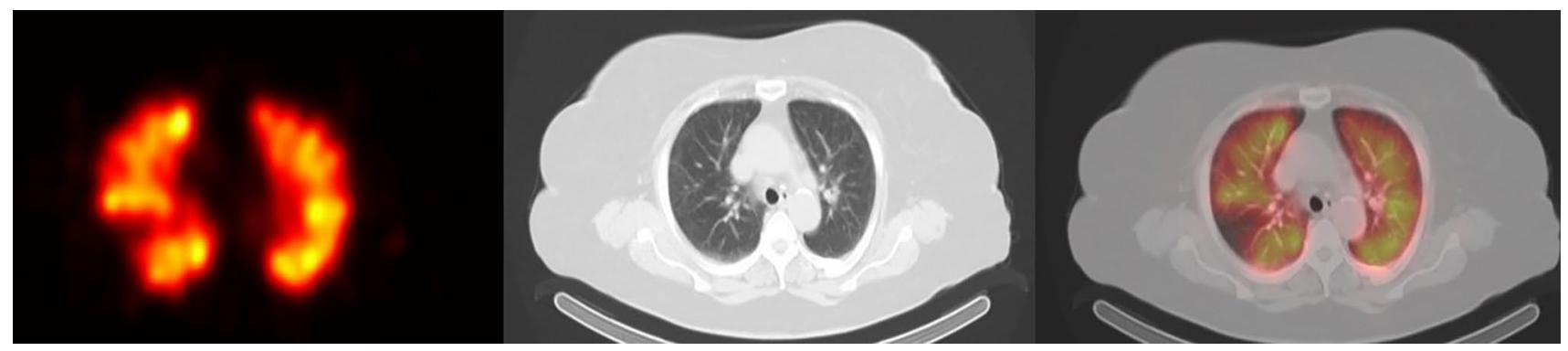

Fig. 1 A sample Q-SPECT/CT images-1. Image 1: Perfusion defect with segmental wedge-style in the superior segment of the lower lobe of the right lung, incompatible with $\mathrm{CT}$

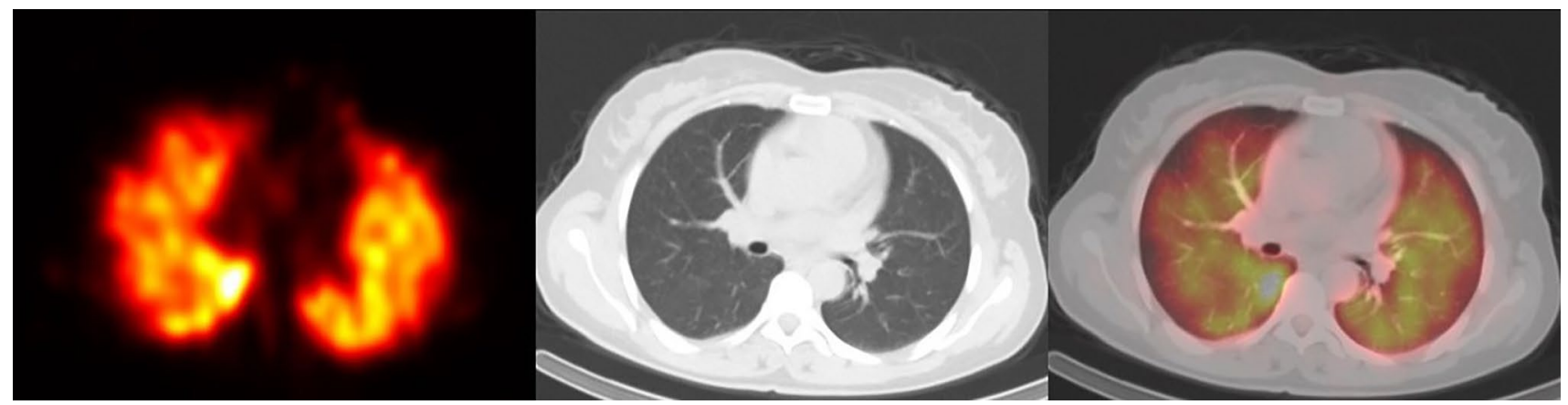

Fig. 2 A sample Q-SPECT/CT images-2. Image 2: Multiple peripherally located subsegmental perfusion defects in bilateral lung parenchyma areas, incompatible with CT

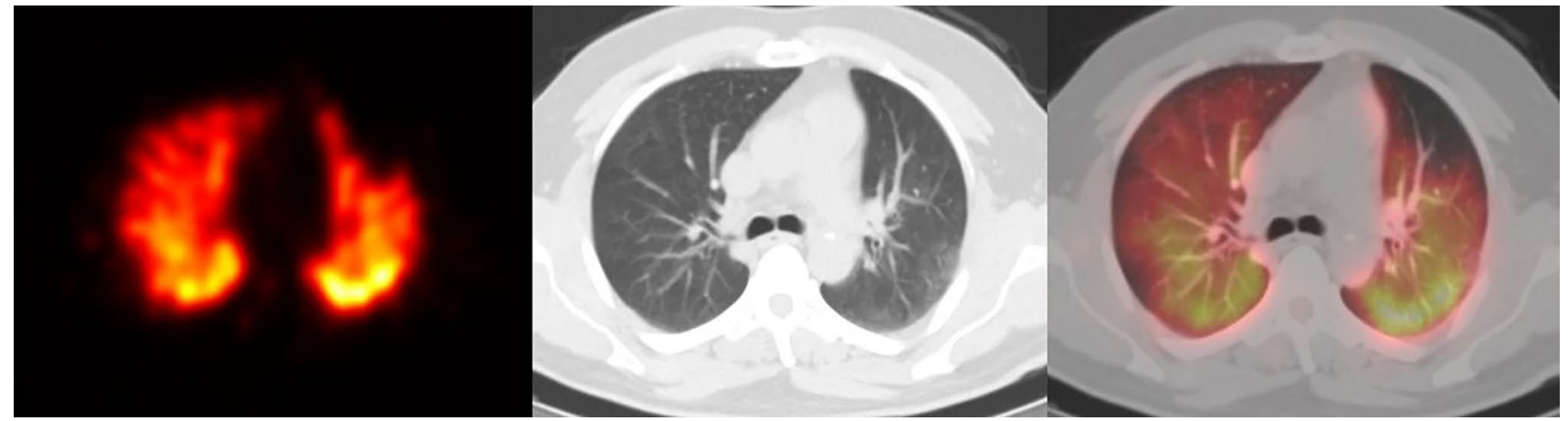

Fig. 3 A sample Q-SPECT/CT images-3. Image 3: Segmentary perfusion defect in the upper lobe anterior segment of the left lung, incompatible with CT

or high D-dimer reasons, so it does not reflect the overall post-COVID population's symptom rate.

In the literature, studies are examining the relationship between D-dimer and COVID-19 prognosis and PE. Ning Tang et al. [17] showed that D-dimer's elevation in hospitalized patients is associated with poor prognosis. Mong How Ooi et al. [18] in the study conducted on 974 COVID-19 patients from 5 different centers, D-dimer was significantly higher in PE patients than those without PE. A statistically significant relationship was found in our study between elevated D-dimer and PD in mild-to-moderate outpatient COVID-19 patients. PD risk was found 3.4 times higher in patients with D-dimer positivity $(>1 \mathrm{mg} / \mathrm{dL}$ ) than those without D-dimer positivity. This result of our study was published by Mong How Ooi et al. [18] however, our study's difference is that this result was only shown in the mild to the moderate patient group.

Alberto Alonso-Fernández et al. [19] in screening with CTPA in hospitalized COVID-19 patients with D-dimer $>1 \mathrm{mg} / \mathrm{dL}$; The frequency of PE was $50 \%$. In our 
Table 2 Relation between suspected perfusion defect and the type of involvement

\begin{tabular}{|c|c|c|c|}
\hline & $\begin{array}{l}\text { Subsegment } \\
\text { ( } n, \% \text { or } \mathrm{SD})\end{array}$ & $\begin{array}{l}\text { Segment } \\
(n, \% \text { or } \mathrm{SD})\end{array}$ & $p$ Value \\
\hline & $n=19$ & $n=9$ & \\
\hline Number of subsegments held & $\begin{array}{l}1 \pm 1 \\
1(1-3)\end{array}$ & $\begin{array}{l}2 \pm 2 \\
1(0-5)\end{array}$ & $0.885^{\mathrm{a}}$ \\
\hline Number of segments held & - & $\begin{array}{l}2 \pm 1 \\
2(1-5)\end{array}$ & \\
\hline PE suspicion & & & $1^{\mathrm{b}}$ \\
\hline $\begin{array}{l}\text { Laboratory (D-dimer } \geq 1 \mathrm{mg} / \\
\text { dL) }\end{array}$ & $3(15.8)$ & $2(22.2)$ & \\
\hline Clinical (dispnea/chest pain) & $7(36.8)$ & $3(33.3)$ & \\
\hline Laboratory + Clinical & $9(47.4)$ & $4(44.4)$ & \\
\hline
\end{tabular}

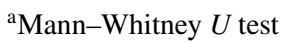

${ }^{\mathrm{b}}$ Fisher's exact test

Table 3 Conditions that increase the risk of perfusion defect

\begin{tabular}{llll}
\hline & OR & $\% 95$ CI & $p$ value \\
\hline $\begin{array}{c}\text { D-dimer }>1 \mathrm{mg} / \\
\text { dL }(\text { Reference: }\end{array}$ & 3.388 & $1.283-8.950$ & $\mathbf{0 . 0 1 4}$ \\
D-dimer $<1 \mathrm{mg} / \mathrm{dL})$ & & & \\
PE suspicion (reference: & & & \\
$\quad$ clinical suspicion) & 2.286 & $0.593-8.813$ & 0.230 \\
$\begin{array}{c}\text { Laboratory suspicion } \\
\quad \text { (D-dimer }>1 \text { mg/dL) }\end{array}$ & 4.160 & $1.401-12.349$ & $\mathbf{0 . 0 1 0}$ \\
$\begin{array}{c}\text { Clinical +laboratory } \\
\text { suspicion }\end{array}$ & & & \\
\hline
\end{tabular}

$O R$ odds ratio, $P D$ perfusion defect

study, perfusion defect without CT abnormality was found in $41.7 \%$ of outpatients who were asymptomatic and had only high D-dimer levels ( $>1 \mathrm{mg} / \mathrm{dL}$ ). Like hospitalized patients, outpatients and patients with low clinical probability have D-dimer $>1 \mathrm{mg} / \mathrm{dL}$ associated with an increased PE risk.

On the other hand, in our study, because D-Dimer levels were $<1 \mathrm{mg} / \mathrm{dL}$ and they were symptomatic, the frequency of PD was found to be $23.8 \%$ in patients who underwent Q-SPECT/CT, and the sensitivity for D-dimer $=1 \mathrm{mg} / \mathrm{dL}$ cut off was found to be $64 \%$. With these findings, it can be concluded that low D-dimer level does not exclude PD in symptomatic patients with a mild-to-moderate course of COVID-19.

Sofia Ventura-Díaz et al. [20] found that in patients with COVID-19, they could predict PE risk with a sensitivity of $81 \%$ above the cut-off value of $0.29 \mathrm{mg} / \mathrm{dL}$ for D-dimer. In our study, the mean D-dimer of PE patients was $2.6 \pm 3.9 \mathrm{mg} /$ $\mathrm{dL}$, and the sensitivity for D-dimer $=0.7 \mathrm{mg} / \mathrm{dL}$ cut-off was $81 \%$. The results of our study differ from Sofia Ventura-Díaz person with D-dimer cut-off for $81 \%$ sensitivity.

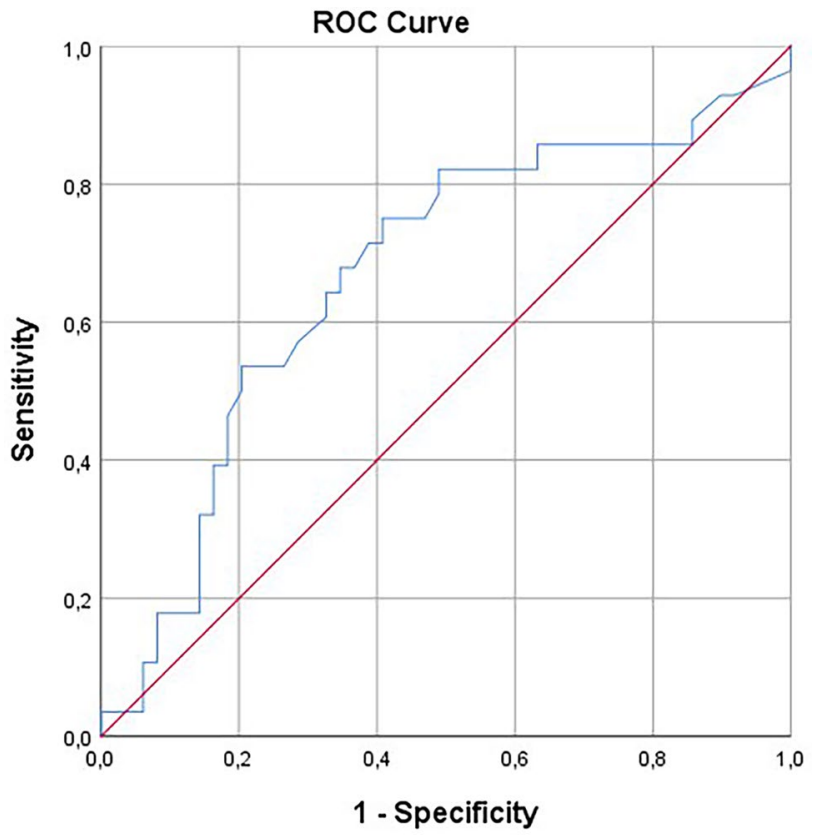

Diagonal segments are produced by ties.

Fig. 4 D-dimer ROC curve. The test result variable (s): Q-SPECT/ CT, D-dimer, has at least one tie between the positive actual and negative actual state groups. The smallest cut-off value is the minimum observed test value minus 1 , and the most considerable cut-off value is the maximum observed test value plus 1 . All the other cut-off values are the averages of two consecutive ordered observed test values

COVID-19; can predispose patients to thrombotic complications due to excessive inflammation, platelet activation, endothelitis, and stasis [21]. Studies have shown that PE progresses with peripherally located microthrombi [22-24]. PE due to COVID-19 is mostly in the peripheral areas; it supports that thrombus emerges at microvascular levels with vascular damage rather than migration to the pulmonary vascular area [25]. None of the 28 patients who were found to have PD by Q-SPECT/CT had a perfusion defect located more centrally than the segment level in our study. All defects were at the segment or sub-segment level. Segment involvement was present in $32.1 \%(n=9)$ and subsegment involvement in $67.9 \%(n=19)$ of the patients in the PD group. These findings of our study support that PD is mostly in the peripheral area in COVID-19 patients.

With various studies, PE frequency in severe and critically ill patients varies between 23 and $31 \%$. Franck Grillet et al. [1] showed that $23 \%$ of patients with COVID-19 hospitalized with severe clinical presentation or comorbidity had acute PE on screening with CTPA. Corrado Lodigiani et al. [2] $7.7 \%$ of all patients, $27.6 \%$ of ICU patients, and $6.4 \%$ of ward patients showed that a thromboembolic event developed. Frederikus Klok et al. [3] reported thrombotic complications in 31\% of COVID-19 patients in the intensive care unit. Beatriz Mestre-Gómez et al. [26] found the prevalence 
of PE with CTPA as $31.9 \%$ in hospitalized patients. Because of this high frequency of PD, embolism prophylaxis with anticoagulants is recommended for all inpatients diagnosed with COVID-19 during hospitalization and discharge [27, 28]. However, there is no study comparing PE prevalence in COVID patients with mild and moderate outpatient followup. Since the risk of embolism is unknown, anticoagulant prophylaxis is not recommended for these patients. Our study has shown that; The prevalence of PD with no concomitant CT abnormality is $36.6 \%$ in the presence of symptoms and/or high D-dimer levels in patients with mild and moderate COVID-19.

Moreover, all of these patients are patients with low clinical probability. The fact that the thrombosis risk in nonhospitalized patients is similar to hospitalized and immobile patients shows that SARS-CoV-2 increases the risk of thrombosis in every patient regardless of the severity of the disease. This high microembolism rate indicates that prophylaxis should also be considered in outpatients, even if the disease is mild.

Limitations: Q-SPECT/CT may have been preferred in the first place due to the selection bias in outpatient patients with low clinical probability for PE due to the intensive COVID19 admissions and the density of the CT unit. Q-SPECT/CT may be a more sensitive method than $\mathrm{CT}$ angio in showing small thrombi. Since CTPA cannot be taken to the same patient due to the additional radiation dose, we do not have a comparative result with CTPA. Since our study was a retrospective study, it was unknown whether the patients received anticoagulant prophylaxis or not. The relationship between anticoagulant prophylaxis and PE development could not be examined. The low number of cases is a limitation, and there is a need for studies with more extensive series on this subject.

Our study's strengths are significant in that it is the first study investigating PD without concomitant CT changes in outpatients with mild-to-moderate COVID-19 with Q-SPECT/CT.

\section{Conclusion}

In conclusion, Q-SPECT/CT is an effective first-choice imaging method in diagnosing pulmonary microembolism in the post-COVID period. In patients with persistent high D-dimer level and/or dyspnea / exertional dyspnea in the post-COVID period, segment and subsegment involvement PD should be considered even if the Wells score is low, and further investigations should be performed. Thrombosis tendency is also present in outpatients with mild-to-moderate COVID-19, and these patients should also be offered anticoagulant prophylaxis during the COVID-19 period.
Funding No funds, grants, or other support war received.

\section{References}

1. Grillet F, Behr J, Calame P, Aubry S, Delabrousse E. Acute pulmonary embolism associated with COVID-19 pneumonia detected with pulmonary CT angiography. Radiology. Radiology Radiol Soc N Am. 2020;296:E186-8. https://doi.org/10.1148/radiol. 2020201544.

2. Lodigiani C, Iapichino G, Carenzo L, Cecconi M, Ferrazzi P, Sebastian T, et al. Venous and arterial thromboembolic complications in COVID-19 patients admitted to an academic hospital in Milan, Italy. Thromb Res. 2020;191:9-14. https://doi.org/10. 1016/j.thromres.2020.04.024.

3. Klok FA, Kruip MJHA, van der Meer NJM, Arbous MS, Gommers DAMPJ, Kant KM, et al. Incidence of thrombotic complications in critically ill ICU patients with COVID-19. Thromb Res. 2020;191:145-7. https://doi.org/10.1016/j.thromres.2020.04.013.

4. Guideline C. Diagnosis and treatment protocol for novel coronavirus pneumonia (Trial version 7). Chin Med J (Engl). 2020;133:1087-95. https://doi.org/10.1097/CM9.0000000000 000819 .

5. Gervaise A, Bouzad C, Peroux E, Helissey C. Acute pulmonary embolism in non-hospitalized COVID-19 patients referred to CTPA by emergency department. Eur Radiol Eur Radiol. 2020;30:6170-7. https://doi.org/10.1007/s00330-020-06977-5.

6. Lu Y, Lorenzoni A, Fox JJ, Rademaker J, Els NV, Grewal RK, et al. Noncontrast perfusion single-photon emission CT/CT scanning. Chest. 2014;145:1079-88. https://doi.org/10.1378/chest. 13-2090.

7. Bajc M, Schümichen C, Grüning T, Lindqvist A, Le Roux PY, Alatri A, et al. EANM guideline for ventilation/perfusion singlephoton emission computed tomography (SPECT) for diagnosis of pulmonary embolism and beyond. Eur J Nucl Med Mol Imaging. 2019;46:2429-51. https://doi.org/10.1007/s00259-019-04450-0.

8. Lu Y, Macapinlac HA. Perfusion SPECT/CT to diagnose pulmonary embolism during COVID-19 pandemic. Eur J Nucl Med Mol Imaging. 2020;47:2064-5. https://doi.org/10.1007/ s00259-020-04851-6.

9. Kumar N, Xie K, Mar W, Anderson TM, Carney B, Mehta N, et al. Software-based hybrid perfusion SPECT/CT provides diagnostic accuracy when other pulmonary embolism imaging is indeterminate. Nucl Med Mol Imaging. 2010;2015(49):303-11. https://doi. org/10.1007/s13139-015-0359-8.

10. Burger IA, Niemann T, Patriki D, Fontana F, Beer JH. Is there a role for lung perfusion [99mTc]-MAA SPECT/CT to rule out pulmonary embolism in COVID-19 patients with contraindications for iodine contrast? Eur J Nucl Med Mol Imaging. 2020;47:20623. https://doi.org/10.1007/s00259-020-04837-4.

11. Vöö S, Neriman D, Henry M, Kayani I. Perfusion-ventilation imaging in an era of COVID-19. Nucl Med Commun. 2020. https://doi.org/10.1097/MNM.0000000000001201.

12. Burger IA, Niemann T, Patriki D, Fontana F, Beer JH. Lung perfusion [99mTc]-MAA SPECT/CT to rule out pulmonary embolism in COVID-19 patients with contraindications for iodine contrast. Eur J Nucl Med Mol Imaging. 2020;47:2209-10. https://doi.org/ 10.1007/s00259-020-04862-3.

13. Vöö S, Dizdarevic S. Single photon emission computed tomography-computed tomography lung perfusion imaging during the COVID-19 pandemic: does nuclear medicine need to reconsider its guidelines? Nucl Med Commun. 2020. https://doi.org/10.1097/ MNM.0000000000001246.

14. Das JP, Yeh R, Schöder H. Clinical utility of perfusion (Q)single-photon emission computed tomography (SPECT)/CT for 
diagnosing pulmonary embolus (PE) in COVID-19 patients with a moderate to high pre-test probability of PE. Eur J Nucl Med Mol Imaging. 2020. https://doi.org/10.1007/s00259-020-05043-y.

15. van der Hulle T, Cheung WY, Kooij S, Beenen LFM, van Bemmel T, van Es J, et al. Simplified diagnostic management of suspected pulmonary embolism (the YEARS study): a prospective, multicentre, cohort study. Lancet. 2017;390:289-97. https://doi.org/10. 1016/S0140-6736(17)30885-1.

16. Carfî A, Bernabei R, Landi F. Persistent symptoms in patients after acute COVID-19. JAMA. 2020;324:603-5. https://doi.org/ 10.1001/jama.2020.12603.

17. Tang N, Li D, Wang X, Sun Z. Abnormal coagulation parameters are associated with poor prognosis in patients with novel coronavirus pneumonia. J Thromb Haemost. 2020;18:844-7. https://doi. org/10.1111/jth.14768.

18. Ooi MWX, Rajai A, Patel R, Gerova N, Godhamgaonkar V, Liong SY. Pulmonary thromboembolic disease in COVID-19 patients on CT pulmonary angiography: prevalence, pattern of disease and relationship to D-dimer. Eur J Radiol. 2020;132:109336. https:// doi.org/10.1016/j.ejrad.2020.109336.

19. Alonso-Fernández A, Toledo-Pons N, Cosío BG, Millán A, Calvo N, Ramón L, et al. Prevalence of pulmonary embolism in patients with COVID-19 pneumonia and high D-dimer values: a prospective study. PLoS ONE. 2020;15:1-15. https://doi.org/10.1371/ journal.pone.0238216.

20. Ventura-Díaz S, Quintana-Pérez JV, Gil-Boronat A, Herrero-Huertas M, Gorospe-Sarasúa L, Montilla J, et al. A higher D-dimer threshold for predicting pulmonary embolism in patients with COVID-19: a retrospective study. Emerg Radiol Emerg Radiol. 2020;27:679-89. https://doi.org/10.1007/s10140-020-01859-1.

21. Bikdeli B, Madhavan MV, Jimenez D, Chuich T, Dreyfus I, Driggin E, et al. COVID-19 and thrombotic or thromboembolic disease: implications for prevention, antithrombotic therapy, and follow-up: JACC state-of-the-art review. J Am Coll Cardiol. 2020;75:2950-73. https://doi.org/10.1016/j.jacc.2020.04.031.

22. Asakura H, Ogawa H. COVID-19-associated coagulopathy and disseminated intravascular coagulation. Int J Hematol. 2021;113:45-57. https://doi.org/10.1007/s12185-020-03029-y.
23. Chen W, Pan JY. Anatomical and pathological observation and analysis of SARS and COVID-19: microthrombosis is the main cause of Death. Biol Proced Online Biol Proced Online. 2021;23:1-12. https://doi.org/10.1186/s12575-021-00142-y.

24. Della Rocca DG, Magnocavallo M, Lavalle C, Romero J, Forleo GB, Tarantino N, et al. Evidence of systemic endothelial injury and microthrombosis in hospitalized COVID-19 patients at different stages of the disease. J Thromb Thrombolysis. 2020. https:// doi.org/10.1007/s11239-020-02330-1.

25. Beenen LFM, Bos LD, Scheerder MJ, Lobé NHJ, Muller MCA, Schultz MJ, et al. Extensive pulmonary perfusion defects compatible with microthrombosis and thromboembolic disease in severe Covid-19 pneumonia. Thromb Res. 2020;196:135-7. https://doi. org/10.1016/j.thromres.2020.08.026.

26. Mestre-Gómez B, Lorente-Ramos RM, Rogado J, Franco-Moreno A, Obispo B, Salazar-Chiriboga D, et al. Incidence of pulmonary embolism in non-critically ill COVID-19 patients. Predicting factors for a challenging diagnosis. J Thromb Thrombolysis. 2021;51:40-6. https://doi.org/10.1007/s11239-020-02190-9.

27. Moores LK, Tritschler T, Brosnahan S, Carrier M, Collen JF, Doerschug K, et al. Prevention, diagnosis, and treatment of VTE in patients with Coronavirus disease 2019: CHEST Guideline and Expert Panel Report. Chest. 2020;158:1143-63. https://doi.org/ 10.1016/j.chest.2020.05.559.

28. Rentsch CT, Beckman JA, Tomlinson L, Gellad WF, Alcorn C, Kidwai-Khan F, et al. Early initiation of prophylactic anticoagulation for prevention of coronavirus disease 2019 mortality in patients admitted to hospital in the United States: Cohort study. BMJ. 2019;2021:372. https://doi.org/10.1136/bmj.n311.

Publisher's Note Springer Nature remains neutral with regard to jurisdictional claims in published maps and institutional affiliations. 